\section{LA DIFUSIÓN DE LAS FÓRMULAS RENACENTISTAS DENTRO DEL CAMPO DE CALATRAVA: ALONSO GALDÓN Y LA PARROQUIA DE MANZANARES}

THE DIFFUSION OF THE RENAISSANCE FORMULAS WITHIN THE CAMPO DE CALATRAVA: ALONSO GALDÓN AND THE PARISH CHURCH OF MANZANARES

LA DIFFUSION DES FORMULES DE LA RENAISSANCE DANS LE CAMPO DE CALATRAVA: ALONSO GALDÓN ET LA PAROISSE DE MANZANARES

RESUMEN: Este trabajo aporta nueva información sobre la ampliación de la parroquia de Manzanares (Ciudad Real) y la construcción de su portada renacentista, uno de los mayores conjuntos escultóricos del Campo de Calatrava, analizando el importante papel que desempeñaron canteros de origen vasco en todo este proceso.

PALABRAS CLAVE: Parroquia; Manzanares; Alonso Galdón; siglo $\mathrm{XVI}$; arquitectura; escultura.
ABSTRACT: This work provides new information on the extension of the parish church of Manzanares (Ciudad Real) and the construction of its Renaissance cover, one of the largest sculptural ensembles in the Campo de Calatrava, analyzing the important role played by stonemasons of Basque origin throughout this process.

KEYWORDS:Parish church Manzanares; Alonso Galdón; XVIth century; Architecture; Sculpture.

\section{BARRANQUERO CONTENTO, José Javier}

IES Fray Andrés

Copa, n.․ 1

13500 Puertollano (Ciudad Real) javierbarranquero@hotmail.com ORCID ID: 0000-0003-4811-6857

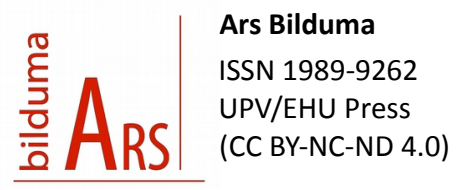

MOTS-CLÉS: Église, Manzanares, Alonso Galdón, XVle siècle, Architecture, Sculpture.
RÉSUMÉ: Ce travail fournit de nouvelles informations sur l'extension de la paroisse de Manzanares (Ciudad Real) et la construction de la façade Renaissance, I'un des plus grands ensembles sculpturaux de Campo de Calatrava, analyse le rôle importan joué par les tailleurs de pierre d'origine basque dans ce processus. https://doi.org/10.1387/ars-bilduma.17965 BIBLID [(2018), 8; 63-82]

Recep.: 30/06/2017 Acept.19/10/2017 


\section{INTRODUCCIÓN}

La parroquia de Nuestra Señora de la Asunción de Manzanares era un magnífico edificio que combinaba los planteamientos tardogóticos con las nuevas fórmulas renacentistas. El recinto fue incendiado durante la Guerra Civil, perdiéndose las numerosas obras de arte que guardaba en su interior y sufriendo graves daños estructurales. Las bóvedas se hundieron, pero los muros perimetrales resistieron, conservándose de esta forma uno de los mayores conjuntos escultóricos de todo el Campo de Calatrava, la portada principal o del Sol. A lo largo de este trabajo analizaremos la historia constructiva del edificio centrándonos en las intervenciones que tuvieron lugar a lo largo del siglo XVI, intervenciones en las que desempeñaron un papel muy importante canteros de origen vasco.

\section{LA AMPLIACIÓN DE MEDIADOS DEL SIGLO XVI}

La parroquia Manzanares se levantó entre finales del siglo XV y principios del $X \mathrm{XI}^{1}$. Sin embargo, el rápido crecimiento de la población que experimentó la localidad hizo que el edificio se quedase pequeño y que los miembros del concejo tomasen la decisión de ampliarlo. La intervención dio lugar a la construcción de una nueva capilla mayor que constaba de un ábside pentagonal y de un crucero. Los pocos datos que teníamos sobre este proyecto procedían de la visita que realizaron a la iglesia los representantes de la Orden de Calatrava en $1565^{2}$, pero el hallazgo de

1 FERNÁNDEZ-PACHECO SÁNCHEZ-GIL, C.: “El urbanismo en la Orden de Calatrava: el ejemplo de Manzanares (siglos XIII-XVII), en ALIA MIRANDA, F. y ANAYA FLORES, J.: I Congreso Nacional Ciudad Real y su provincia, Tomo I, Ciudad Real, Instituto de Estudios Manchegos, 2015, p. 184.

2 BARRANQUERO CONTENTO, J.J.: "La arquitectura en el Campo de Calatrava (15001570): de Juan de Baeza y Antón Egas a Enrique Egas el Mozo y Martín de Zalvilla”, nuevas fuentes documentales nos ha brindado la posibilidad de conocer con mucha más profundidad este proceso. Como en otras ocasiones, los datos proceden del pleito que se entabló en 1567 entre el concejo y el comendador de la localidad para que éste último, como perceptor de la mayor parte de los diezmos, ayudase a costear la obra ${ }^{3}$.

Las gestiones para poner en marcha el nuevo proyecto comenzaron en 1554. Los visitadores que llegaron ese año a la localidad comprobaron "la estrechura que avia de gente en la dicha yglesya por el cresçimiento que avia de gente en esta villa y que cada dia cresçia mas y la neçesydad que avia por las dichas causas de cresçer la dicha yglesya y (...) lo trataron con los oficiales del conçejo y les dixeron que todo el pueblo tenie muy gran boluntad y gana que se hiziese una capilla mayor delante de la que agora estado tomando la casa del benefiçio para ello y que pensaban dar aviso dello a don Alonso de Aguilar comendador desta villa para que ayudase para hazer la capilla mayor y del presçio que se devia de hazer". Los visitadores vieron con buenos ojos la ampliación y conminaron a todo el pueblo a esforzarse "como personas tan honrradas y de tanta caridad y cristiandad a dar horden como se hiziese la dicha capilla y dar parte dello al dicho Alonso de Aguilar pidiendole que ayudase para la dicha obra" ${ }^{4}$.

Sin embargo, la génesis del proyecto fue mucho más compleja de lo que hasta ahora se conocía porque, en un primer momento, los miembros del concejo barajaron dos posibilidades para dar respuesta a la falta de espacio en la iglesia: ampliar el edificio ya existente o construir una segunda

Archivo Español de Arte, tomo 86, no 341, 2013, pp. 15-28.

3 Archivo histórico Nacional (en adelante AHN), Órdenes Militares (en adelante OOMM), Archivo histórico de Toledo, legajo 41492, sf.

4 AHN, OOMM, legajo 6082/ 14, sf. 
parroquia, como estaban haciendo en la vecina localidad de Daimiel ${ }^{5}$. Al final se optó por agrandar el edificio y parece que la decisión se adoptó en torno a 1563 porque varios de los testigos que declararon en 1567 coinciden en afirmar que la determinación de construir la nueva capilla mayor se había tomado unos cuatro años antes ${ }^{6}$.

Hasta ahora sabíamos que la cabecera fue diseñada por Enrique Egas el Mozo, pero la documentación consultada nos ha permitido conocer que, en realidad, las trazas fueron realizadas por este maestro y por otro que había permanecido en la sombra. Se trata de Alonso Galdón, maestro de cantería de origen vizcaíno. El propio Alonso lo dejó bien claro en su declaración al afirmar que "avra quatro años poco mas o menos que se acordo por el conçejo desta villa de hazer un trascoro de quatro capillas para agrandar la dicha yglesia la qual traçaron maestre Enrrique Egas mastre del dicho arte del quytitura vezino de Almagro y este testigo e luego se traçaron las çanjas" ${ }^{7}$. La respuesta que acabamos de transcribir es el primer y único testimonio documental que tenemos sobre la colaboración de ambos maestros en un mismo proyecto. La actividad que

5 Sabemos que se barajaron estas dos opciones gracias a la declaración de Alonso Martín Carnicero uno de los testigos que fueron interrogados en 1567.

6 En muchas ocasiones, el expediente se refiere a la nueva capilla mayor con el término trascoro. En este sentido, nos gustaría precisar que no es la primera vez que en la documentación generada por la Orden de Calatrava se utiliza la palabra coro para hacer referencia a la cabecera de la iglesia.

7 AHN, OOMM, Archivo histórico de Toledo, legajo 41492, sf. Las palabras de Alonso quedaron corroboradas por las de otro testigo, Roque García Serrano, que afirmó que "al tienpo que se acordo lo susodicho (agrandar la iglesia) vido que truxeron a mase Enrrique e a Galdon maestros de canteria los quales dieron la traça dello e se lo pagaron". Su origen vasco queda atestiguado en uno de los pagos que recibió por su trabajo en la obra de la iglesia, concretamente el realizado el 1 de septiembre de 1566, en el que se dice expresamente que era vizcaíno. desarrolló Enrique Egas el Mozo en el Campo de Calatrava está bastante bien documentada gracias a la reciente publicación de varios trabajos. Enrique llegó a la localidad de Almagro en torno a 1530 para hacerse cargo de la fábrica del monasterio de Nuestra Señora de la Asunción y desempeñó un papel muy importante en el desarrollo de la arquitectura de la comarca durante el segundo tercio del siglo XVI; ya que realizó una traza para continuar la obra de la parroquia de Madre de Dios, también en Almagro, y diseñó la nueva capilla mayor de la parroquia de Argamasilla de Calatrava ${ }^{8}$.

La figura de Alonso Galdón está menos estudiada. Hasta ahora, de su actividad en la zona sólo conocíamos su intervención en el diseño y construcción de la primitiva torre de la parroquia de La Solana, obra en la que aparece asociado a otro maestro llamado Lope de Arranguez ${ }^{9}$. Sin embargo, gracias a la documentación encontrada hemos podido conocer varios datos biográficos de gran interés ya que el propio Alonso declaró que contaba con cincuenta y cuatro años (es decir, que habría nacido en torno a 1513) y que conocía la villa de Manzanares "de veinte años a esta parte que a que se caso en ella aunques vezino de Daymiel" ${ }^{10}$

8 BARRANQUERO CONTENTO, J.J.: Op. cit., pp. 17-24.

9 MOLINA CHAMIZO, P.: De la fortaleza al templo. Arquitectura religiosa de la Orden de Santiago en la provincia de Ciudad Real (siglos XV-XVIII), Tomo II, Ciudad Real, Diputación Provincial de Ciudad Real, 2006, p. 36. Pilar Molina pensaba que Alonso Galdón podría estar muerto en 1563 porque en torno a esta fecha dejó de aparecer en la documentación relativa a la construcción de la torre, pero los datos que aportamos demuestran lo contrario.

10 Aurelio Pretel Marín documentó la presencia de un cantero llamado Alonso Galdón trabajando en Alcaraz entre 1540 y 1456. Este maestro, perteneciente al círculo de Andrés de Vandelvira, construyó la capilla de los Ballesteros de la parroquia de La Trinidad, recinto que se cubre con una bóveda de medio cañón decorada con casetones. Según Pretel Marín, Alonso y la que era su mujer, Mari Rodríguez, bautizaron en 1542 a su hijo Sebastián en la iglesia de La Trinidad, dato que podría 
En relación con el diseño de la nueva capilla mayor de Manzanares, el 22 de mayo de 1563, las cuentas de la iglesia recogen el pago de 4.566 maravedís a Maese Enrique y de 20 reales (680 maravedís) a Alonso Galdón. Los asientos no mencionan el concepto por el que se desembolsaron ambas cantidades, pero parece lógico pensar que fuera por la ejecución de la traza e incluso por marcar sobre el suelo el contorno de los muros ya que poco después de realizarse el pago se abrieron las zanjas de los cimientos. La diferencia en la cuantía de las cantidades entregadas estaría relacionada con la fama o la experiencia profesional de cada uno de los maestros. En este sentido, tendríamos que recordar que en 1546 Enrique Egas recibió una cantidad muy inferior por la traza que hizo para continuar la obra de la iglesia de Madre de Dios de Almagro, diseño por el que tan solo cobró cuatro ducados (1.500 maravedís); por lo que parece obvio que, con el paso del tiempo, el valor de sus honorarios aumentó ostensiblemente ${ }^{11}$. Por otra parte, también sería necesario señalar que la documentación no vuelve a recoger ningún pago a Enrique Egas el Mozo y que el encargado de levantar la capilla fue Alonso, que se refiere a sí mismo como maestro de la obra.

La nueva capilla mayor fue tasada en 2.665 .510 maravedís. El propio Alonso Galdón valoró en 2.263.010 maravedís todo lo "tocante al arte de

resultar contradictorio con la fecha de matrimonio aportada por la documentación que hemos consultado, a no ser que el maestro se hubiera casado en segundas nupcias en torno a 1547, por lo que solo futuras investigaciones podrán determinar si se trata de la misma persona. PRETEL MARIN, A.: Alcaraz en el siglo de Andrés de Vandelvira, el bachiller Sabuco y el preceptor Abril (Cultura, sociedad, arquitectura y otras bellas artes en el Renacimiento), Albacete, Diputación Provincial de Albacete, 1999, pp. 192193 y $199-200$.

11 BARRANQUERO CONTENTO, J.J.: "La fábrica de la Madre de Dios (Almagro): el largo proceso constructivo de un edificio singular", I Congreso Nacional Ciudad Real y su provincia, Vol. 3, Ciudad Real, Instituto de Estudios Manchegos, 2015, p. 91. alquytitura ques arte de canteria", mientras que las labores de carpintería fueron valoradas por Francisco Sánchez, maestro del oficio, que consideró necesarios 402.500 maravedís para rematarlas ${ }^{12}$.

El desarrollo de las tareas constructivas presenta una pequeña particularidad y es que la obtención del material de construcción comenzó mucho antes de que se abrieran los cimientos e incluso antes de que se tomara la decisión de qué proyecto se iba a realizar. Uno de los testigos que declararon en las diligencias hace referencia a este hecho ${ }^{13}$, pero además las cuentas de la iglesia incluyen cincuenta y tres pagos, realizados entre el 29 de mayo de 1561 y el 29 de marzo de 1563, que estaban relacionados con el trabajo de varios maestros que se dedicaban a labrar piedra o a trabajar en la cantera, pagos que en total sumaban más de 107.300 maravedís. La mayor parte de ellos se realizaron a Alonso Galdón como cabeza de una cuadrilla de canteros de origen vizcaíno ${ }^{14}$, pero también nos encontramos con varios efectuados a otros maestros, como Bastián García, Miguel Martín, Juan de Aguirre, Hernando de Arriba (o de la Riba) y un tal Garnica ${ }^{15}$; canteros que en su mayor parte eran vizcaínos,

12 Dentro de esta cantidad se incluían tanto los materiales (madera y clavos) como e sueldo de los oficiales de carpintería que realizasen la tarea.

13 En relación con la cantidad que se habría gastado en la obra, Alonso Martín Carnicero declaró que "antes que se abriesen las çanjas de la dicha obra que avra quatro o çinco años poco mas o menos se avian gastado trezientos o quatroçientos ducados poco mas o menos en abrir la cantera o canteras que para ello se buscaron y en sacar puedra (sic.) e trahella a esta villa e labralla". AHN, OOMM, Archivo histórico de Toledo, legajo 41492, sf.

14 Las anotaciones utilizan varias expresiones para hacer referencia a los miembros de su cuadrilla, refiriéndose en ocasiones a "sus obreros" y en otras a "sus oficiales".

15 En noviembre de 1560 aparecen tres pagos realizados a varios de estos maestros. En concreto, el día 14 se entregaron 720 maravedís a Bastián García y a Miguel Martín el Serrano "de seis días que anduvieron desqubriendo piedras en la cantera a sesenta 
aunque no podamos asegurar que pertenecieran o formasen parte habitualmente de la cuadrilla de Alonso.

Poco tiempo después de efectuarse el pago a Enrique Egas y Alonso Galdón se documentan varios desembolsos relacionados con la compra de herramientas para la obra y con la apertura de las zanjas de los cimientos ${ }^{16}$, pero lo curioso es que una vez excavadas no se iniciaron las obras ${ }^{17}$. Tendremos que esperar hasta el 23 de agosto de 1566 para documentar el

maravedis cada uno"; el 21 se pagaron 2.125 maravedís a Alonso Galdón "e a sus oficiales e a Juan Martin de Torralba e a Vastian Garçia de Juan Alonso"; y el 23 se dieron otros 1.575 maravedís a "Juan de Aguirre e a otros dos sus conpañeros y a Bastian Garçia de Juan Alonso vizcaínos los tres (sic.) conpañeros". En diciembre del mismo año nos volvemos encontrar con otros tres asientos. El primero es del día 8 y recoge el pago de 1.513 maravedís a Juan de Aguirre "e a Hernando de la Rriba e a los demas que se contienen en un libramiento"; el segundo, del día 15, consigna la entrega de 1.853 maravedís a "Juan de Arriba y a Hernando de Aguirre e a otros sus compañeros"; y el tercero es del 17 y menciona el desembolso de 476 maravedís que se dieron a "Juan de Aguirre y Ernando de Arriba y los conpañeros". Finalmente, el 7 de diciembre de 1561 se entregaron 2.310 maravedís a Alonso Galdón "o a Garnyca en su nombre". Al repasar los pagos de 1560 parece obvio que el escribano se equivocó e intercambió el nombre de los canteros en el segundo de los asientos, el realizado el día 15 de diciembre. AHN, OOMM, Archivo histórico de Toledo, legajo 41492, sf.

16 El 21 de agosto de 1563 se pagaron 638 maravedís a Francisco Muñoz de Yeste por la compra de dos picos y unas espuertas "para hazer la obra de la yglesia", y otros 850 maravedís "por el salario de diez dias que se ocupo en rregir la gente quando se abrio la çanja para el trascoro para el trascoro (sic.) de la yglesia". AHN, OOMM, Archivo histórico de Toledo, legajo 41492, sf.

17 Como prueba de lo que acabamos de mencionar las cuentas recogen varios pagos relacionados con el mantenimiento de las zanjas. En concreto, menciona la entrega de dos reales y, posteriormente, de otros cuatro a varios hombres "que anduvieron en la çanja de la yglesia linpiandola", y el desembolso de tres reales más que se dieron a Garnica "Vizcayno porque andubo enderezando la canja de la yglesia del trascoro". AHN, OOMM, Archivo histórico de Toledo, legajo 41492, sf. primer pago relacionado con la construcción de la nueva cabecera ${ }^{18}$, pero a partir de ese momento se suceden los pagos de forma continuada hasta el 3 de mayo de $1567^{19}$. Tal y como ocurría con los asientos anteriores, la mayor parte de los cantidades que se desembolsaron a partir de 1566 se entregaron a Alonso Galdón como cabeza visible de una cuadrilla de canteros vizcaínos ${ }^{20}$. En total recibió veintiocho pagos por un monto total de 97.065 maravedís. Las cuentas, además, vuelven a recoger pagos a otros canteros que también estaban trabajando en la obra. Dos de ellos, Bastián García de Juan Alonso y Juan de Aguirre ${ }^{21}$, ya aparecen mencionados antes de la apertura de los cimientos, pero los otros no. Se trata de Alonso

18 El hecho de que no se trabajase en la capilla mayor no quiere decir que no se realizasen otras obras en la iglesia y que participasen en ellas algunos de los maestros que tenemos documentados. En este sentido, a principios de 1566 se estaba construyendo un nuevo osario y en relación con esta obra nos encontramos con un primer pago de 8 reales a Alonso Galdon por dos días de trabajo, sin especificar qué hizo exactamente, y otro de 28 reales a "Alonso Galdon maestro e a Juan de Aguirre e a Martin de Aguirre de tres dias que andubieron asentando en el osario". AHN, OOMM, Archivo histórico de Toledo, legajo 41492, sf.

19 Con posterioridad a este desembolso, las cuentas recogen otros tres pagos relacionados con la obra pero, por desgracia, carecen de fecha.

$20 \mathrm{Si}$ los asientos anteriores se limitan a mencionar genéricamente a los obreros $u$ oficiales de Galdón, ahora los pagos que recibía el maestro suelen hacer referencia a la procedencia de los hombres que trabajaban para él, utilizando varias expresiones como "pague Alonso Galdon e a los otros sus conpañeros vizcainos", "para el y los vizcainos" o "para el e a sus vizcainos", que era la más frecuente. Además, y como ya hemos dicho, uno de estos desembolsos es el que hace referencia al origen del propio maestro al afirmar que el pago se realizó a "Alonso Galdon vizcaino e a sus conpañeros". AHN, OOMM, Archivo histórico de Toledo, legajo 41492, sf.

21 Bastián García de Juan Alonso recibió 301 reales (10.234 maravedís) por su trabajo y el de su compañero, y Juan de Aguirre obtuvo 1.326 maravedís "porque dio unas piedras sacadas de la cantera del umylladero para la yglesia". AHN, OOMM, Archivo histórico de Toledo, legajo 41492, sf. 
Muñoz y Pedro Hernandez ${ }^{22}$, y de Francisco Aragonés y Francisco Muñoz ${ }^{23}$. Nombres a los que también tendríamos que añadir el de Pero Martínez de Corruchaga, que no se menciona en las cuentas, pero que declaró como testigo en la información que se realizó en abril de $1567^{24}$.

En 1565 los visitadores de la Orden de Calatrava comprobaron que los cimientos de la nueva capilla mayor estaban abiertos y que había labrada mucha cantidad de piedra, y entre otras cosas volvieron a ordenar que "se de notiçia de la dicha obra al señor marques de Priego" ${ }^{25}$. Sin embargo, y a pesar de que el comendador, don Alonso de Aguilar, realizó un par de donaciones, los miembros del ayuntamiento no quedaron satisfechos porque eran demasiado pequeñas para una intervención de tal envergadura ${ }^{26}$. Dos años después, en 1567, los muros de la cabecera poseían ya una altura de cinco varas, pero la parroquia carecía de fondos para proseguir la obra y los miembros del concejo optaron por obligar al comendador de la villa a sufragar los gastos de su fábrica. Con esa intención enviaron una petición al Consejo de Órdenes solicitando apoyo

22 Las cuentas recogen el pago de 1.543 maravedís a Alonso Muñoz y Pedro Hernández "e a otros sus conpañeros que an andado (...) en la dicha obra". AHN, OOMM, Archivo histórico de Toledo, legajo 41492, sf.

23 Estos dos maestros cobraron seis reales (204 maravedís) por dos días que "anduvieron entranbos en la cantera". AHN, OOMM, Archivo histórico de Toledo, legajo 41492, sf.

24 Cuando declaró, este cantero era vecino de La Solana, localidad que pertenecía a la Orden de Santiago y que está situada a poco más de veinte kilómetros de Manzanares. En esta información testificó otro cantero llamado Juan de Guirre que, a nuestro juicio, sería el Juan de Aguirre mencionado en las cuentas, cantero que en esos momentos tenía treinta años y era vecino de Villarrubia de los Ojos, núcleo de población ubicado algo más lejos, a unos treinta y ocho kilómetros de Manzanares.

25 AHN, OOMM, legajo 6082/14, sf.

26 En concreto, tenemos documentada una donación de 200 reales (6.800 maravedís) y otra de 15.000 maravedís. económico, y más concretamente que el comendador "por aora diese y pagase dos myll ducados para la dicha obra y aquellos gastados contribuyese con lo demas que fuese menester para la continuar e acabar", pretensión que fue rechazada por el comendador dando lugar al largo y voluminoso pleito que estamos utilizando en este trabajo.

En un primer momento, los miembros del Consejo valoraron positivamente los argumentos expuestos por el procurador del ayuntamiento de Manzanares $^{27}$. De ahí que, antes de que se emitiese una sentencia definitiva, el ayuntamiento hiciera gestiones para proseguir la obra, gestiones que implicaron un cambio en la dirección de la misma. Y es que los miembros del concejo solicitaron a otro maestro que redactase unas nuevas condiciones con las que proseguir la nueva capilla mayor, respetando eso sí, la traza original de Enrique Egas el Mozo. El cantero en cuestión fue Juan de Rigoz, personaje que en esos momentos residía provisionalmente en la localidad de Alcázar de San Juan y que presentó las nuevas condiciones el 19 de febrero de $1568^{28}$. Juan valoró el coste de la

27 En la documentación se conserva una anotación que carece de fecha y que recogería e primer parecer de los miembros del Consejo, parecer que fue más favorable que la sentencia definitiva porque obligaba al comendador y al arzobispo de Toledo a pagar 600 ducados durante un período de cinco años, 400 ducados el comendador y 200 el arzobispo. Los miembros del Consejo determinaron también que la iglesia debía gastar en la obra "Io que tiene en dinero y trigo de la fabrica" y que el ayuntamiento "ayude con carretas obreros y peones como lo ha hecho hasta aqui", precisando que la ampliación debía quedar terminada en los cinco años ya mencionados. AHN, OOMM, Archivo histórico de Toledo, legajo 41492, sf.

28 El hecho de que los miembros del concejo se pusieran en contacto con este maestro quedó de manifiesto en el propio encabezamiento de las condiciones, en donde se afirma: "Muy magnificos señores Juan de Rrigoz maestro de canteria hestante en la villa de Alcacar y su tierra digo que por vuesas merçedes me fue mandado que hiciese condiçiones para la obra del trascoro de la yglesia perroquial desta villa de Mancanares digo que conforme a una traça que paresce aber dado maestre Enrrique vezino de 
obra en 2.500 ducados (937.500 maravedís), cantidad en la que solo entraba la mano de obra del propio maestro, porque el pago y transporte de todos los materiales, a excepción de la piedra, debía correr por cuenta del concejo ${ }^{29}$. El maestro se comprometía a terminar la capilla mayor en el plazo de cuatro años, precisando que habría de "dar la dicha obra dentro de tres años subidas las paredes y cerrados los arcos y echado el tablamento que se entiende una cornyxa dorica conforme a el arte de jumetria", y que cerraría las bóvedas al año siguiente ${ }^{30}$. Las condiciones hacen referencia a la introducción de cambios en la traza original, cambios realizados por el propio Enrique Egas el $\mathrm{Mozo}^{31}$, y recogían la necesidad de llamar a otro maestro cuando fueran a levantarse los arcos, cláusula que estaría relacionada con la dificultad de realizar los arranques o jarjamentos, tarea que resultaba especialmente delicada al tener que ligar las molduras de los arcos a las de los capiteles ${ }^{32}$.

Almagro maestro de canteria". AHN, OOMM, Archivo histórico de Toledo, legajo 41492, sf.

29 Juan de Rigoz determinó que "los señores del ayuntamyento (...) me an de dar todos los materiales al pie de la obra traidos a su costa e mysion sacando el maestro la piedra e le an de dar cal y arena y clabos y espuertas e todos los materiales nescesarios tocantes a el arte de la dicha obra que aunquel dicho maestro no sea obligado a poner mas de su persona e sus manos". No obstante, el maestro precisó que "con condiçion que labrare y sacare la piedra de la cantera y la ayudar a cargar en los carros para quel concejo la traiga al pie de la obra e desbastare toda la demas piedra nesçesaria a la obra". AHN, OOMM, Archivo histórico de Toledo, legajo 41492, sf.

30 A este respecto precisó "que dandome todos los materiales para cerrar el casco dare cerrado de todo punto la dicha obra dentro de quatro años". AHN, OOMM, Archivo histórico de Toledo, legajo 41492, sf.

31 Las condiciones estipulaban "que si fuere caso que las enmiendas que son mandadas hacer por el señor mase Enrrique las hare antes que enpiecen a volver nynguno de los arcos encima de los capiteles", aunque desconocemos la naturaleza de estas enmiendas.

32 Sobre este asunto, Juan de Rigoz consideró necesario "que llegada la obra a nybel de

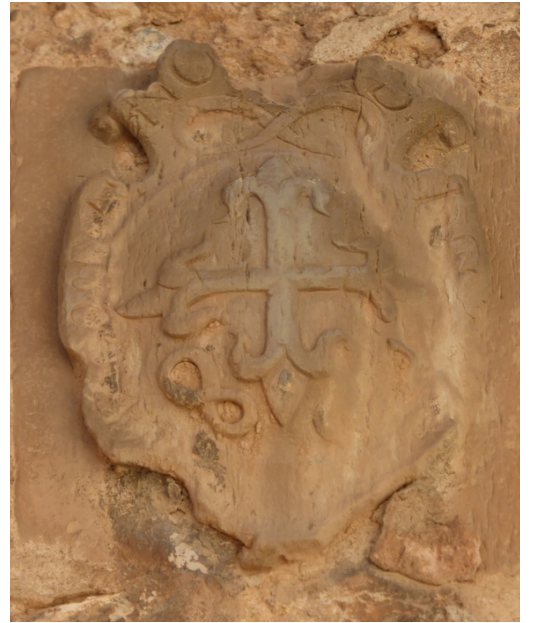

Fig. 1: Escudo del ábside de la parroquia de Nuestra Señora de la Asunción.

Manzanares (Ciudad Real).
El proyecto, además, establecía que se debía "haçer un escudo con unas armas rreales a la traça que diere el maestre Anrrique e un (sic.) cruz de Calatraba a cada parte del hescudo". Esta condición tiene una gran importancia simbólica porque era una clara alusión a la entidad que ostentaba el señorío sobre la zona; de ahí que aunase la heráldica de la orden, como poseedora tradicional de los derechos sobre la villa, con los emblemas de la monarquía, administradora de la propia institución tras la incorporación de maestrazgo. Sin embargo, las instrucciones no se siguieron de forma literal porque, en la actualidad, la capilla mayor cuenta con dos escudos, uno colocado en el paño central del ábside, que muestra una cruz de calatrava (Fig. 1), y otro cuartelado, con las armas de Castilla y León, que se labró en la ventana del crucero que da a la plaza ${ }^{33}$. Finalmente, las condiciones abordaban otros aspectos como la calidad de los materiales a emplear en

los capiteles a donde se an de heligir los arcos e jarjamentos sean obligado el concejo desta villa a traer un maestro de canteria o dos a costa del concejo para que juntamente con el mahestro en quien rrematare la dicha obra eliggan los arcos $y$ enmyenden las faltas de abaxo de manera que la obra vaya perfeta y bien acabado ha visto de los oficiales como dicho es e sy no que sea a costa de la persona en quien rrematare la dicha obra". AHN, OOMM, Archivo histórico de Toledo, legajo 41492, sf.

33 La ventana en su conjunto responde perfectamente a la intencionalidad simbólica que perseguía la condición que acabamos de comentar porque, además de lucir las armas de la monarquía, presenta una cruz de calatrava en el tondo de una de sus enjutas. 
determinados elementos constructivos ${ }^{34}$, la altura que debían tener los contrafuertes $^{35} \mathrm{o}$ la forma de pago.

Juan de Rigoz compareció unos días después de presentar estas condiciones, concretamente el 29 de febrero, y añadió otras nuevas a las ya otorgadas. El maestro introdujo algunas innovaciones, como incorporar el orden jónico en las ménsulas de la capilla mayor ${ }^{36}$, y precisó cómo habría de ser el diseño de la bóveda, aportándonos de paso información sobre la estructura que cubría el último tramo del cuerpo del edificio ${ }^{37}$. Además, las nuevas condiciones acotaban otros aspectos arquitectónicos de la obra, como la altura que debía alcanzar la nueva capilla mayor o las molduras de

34 Las condiciones estipulaban que "si a los oficiales del concejo desta villa les paresçiere que los cruzeros e claves e preçeletes de la dicha obra se hagan de la cantera de Peñarroya o de otra parte que la piedra sea mas ligera que la desta villa quel mahestro en quien se rrematare sea obligado a sacalla e desbastalla y cargalla en los carros quel concejo enbiare por ella para que a costa del concejo se trayga al pie de la obra". AHN, OOMM, Archivo histórico de Toledo, legajo 41492, sf.

35 Juan de Rigoz determinó que "todos los hestribos suban tan alto como las paredes y la cornyja corra toda a la rredonda conforme hesta en el monesterio de San Francisco de la villa de Alcacar". AHN, OOMM, Archivo histórico de Toledo, legajo 41492, sf.

36 Las nuevas condiciones estipulaban que "los dichos maestros en quien rematare la dicha obra a de labrar las rreprisas al rromano bien e con buenas molduras jonycas que vayan sanas e bien tratadas en los rrincones". AHN, OOMM, Archivo histórico de Toledo, legajo 41492, sf.

37 Juan de Rigoz precisó "quel maestro en quien rrematare la dicha obra sea obligado a haçer los cascos de las capillas que correspondan los cruceros e conbados a la capilla de encima de la tribuna de la dicha yglesia e que sean tan costosos e no menos e las claves horadadas para poner filiteras en ellas". Como no disponemos de fotografías antiguas en las que se vea la bóveda, es imposible reconstruir su estructura. No obstante, si tenemos en cuenta la referencia que acabamos de transcribir, podemos afirmar que era más compleja que las que cubrían los dos primeros tramos del edificio. los $\operatorname{arcos}^{38}$, y tenían en cuenta cuestiones de carácter económico y de procedimiento a la hora de realizar su ejecución, con el objetivo de evitar futuros problemas estructurales ${ }^{39}$.

La obra salió a subasta y al proceso de puja se presentaron otros dos maestros, Juan de Arrospide que rebajó el precio en 200 ducados, colocándola en $2.300^{40}$, y Lope de Arranguez que la dejó en 2.150, pero al final se remató en el propio Juan de Rigoz que volvió a rebajarla, dejándola en 2.000 ducados (750.000 maravedís). No obstante, si nos atenemos al remate final, es bastante probable que Juan de Rigoz y Juan de Arrospide no estuvieran compitiendo entre sí, sino que estuvieran de acuerdo, porque al final la obra quedó en manos de ambos maestros ${ }^{41}$.

38 Con respecto al primer asunto, el documento precisaba que "hes condicion questa obra a de suvir mas alta que la bieja ocho pies conforme a la traza de mase Anrrique". En relación con las molduras señalaba que "hes condicion que en los arcos que se an de haçer por lados e por parte de abaxo demas de su mocheta un talon bertiente a la parte de adentro". AHN, OOMM, Archivo histórico de Toledo, legajo 41492, sf.

39 En este sentido, el concejo no tenía que dar ningún peón para trabajar en la fábrica, sino que tan sólo estaba obligado a poner los materiales a pie de obra. Además, el maestro en quien se rematase la obra debía estar presente cuando se colocase la armadura de madera que haría las funciones de tejado.

40 El apellido de este maestro está escrito de cuatro formas distintas en el documento, en la puja aparece como Orozpide y Ardezpide, y en el remate como Arrazpide y Razpide, pero se trata del mismo cantero que está documentado terminando la capilla mayor de la parroquia de Argamasilla de Calatrava. BARRANQUERO CONTENTO, J.J.: "Canteros vascos en el Campo de Calatrava durante la segunda mitad del siglo XVI", Ars Bilduma: Revista del Departamento de Historia del Arte y Música de la Universidad del Pais Vasco, nㅇ 6, 2016, pp. 10-22.

41 Según consta en el documento "por no aber persona que abaxase por mandado de los dichos señores oficiales del concejo se rremato la dicha obra en el dicho Juan de Rrigoz el qual que estava presente rrescibio en sy el rremate e juntamente con el Juan de Rrazpide e anbos a dos se obligaron de hacer obligacion e dar fiancas a contento del concejo". AHN, OOMM, Archivo histórico de Toledo, legajo 41492, sf. 
Tras realizar numerosas diligencias, el Consejo de Órdenes emitió sentencia el 8 de marzo de 1568, condenando al comendador a que "de y page para la obra de la dicha ilesia questa comenzada a hazer myll y duçientos ducados los quales page por tienpo y espaçio de siete años primeros sygientes cadaño por rrata lo que cupiere a los dichos myll y duçientos ducados". El documento no recoge las razones por las que los miembros del Consejo decidieron conceder una cantidad inferior a la recogida en la tasación, pero lo más probable es que tuvieran en cuenta la capacidad económica de la propia parroquia ${ }^{42}$. No obstante, y a pesar de que esta decisión rebajaba la cantidad a pagar, el procurador del comendador recurrió la sentencia afirmando, entre otras cosas, que la parte contraria había aportado información falsa, engañando a los miembros del Consejo. A este respecto, argumentaba que la obra se había tasado en 2.000 ducados, cantidad muy inferior a lo expuesto en un primer momento por el concejo, ya que la petición que dio origen al proceso afirmaba que se habían invertido más de mil ducados en la ampliación y que serían necesarios otros ocho o nueve mil para terminarla. Obviamente, el procurador del ayuntamiento rechazó estos argumentos y solicitó que se despachase la ejecutoria de la sentencia, decisión que se adoptó el 1 de abril $1568^{43}$.

42 El procurador del comendador trató de probar la solvencia económica de la iglesia por lo que presentó un memorial en el que se enumeraban los bienes que poseía con el objetivo de que, tanto los testigos presentados por él como los miembros del concejo, certificasen si era verdad que contaba con estos recursos. El documento afirmaba, entre otras cosas, que la iglesia poseía más de mil fanegas de trigo, que las sepulturas de la nueva capilla mayor podrían venderse por unos mil ducados, y que los distintos bienes raíces que tenía podrían valer otros mil más. Sobre este asunto, el mayordomo de la iglesia declaró que la fábrica tenía 170.300 maravedís y 334 fanegas de trigo, aunque no pudo precisar ni el valor de las hazas que eran propiedad de la parroquia, ni el de las sepulturas de la nueva capilla mayor.

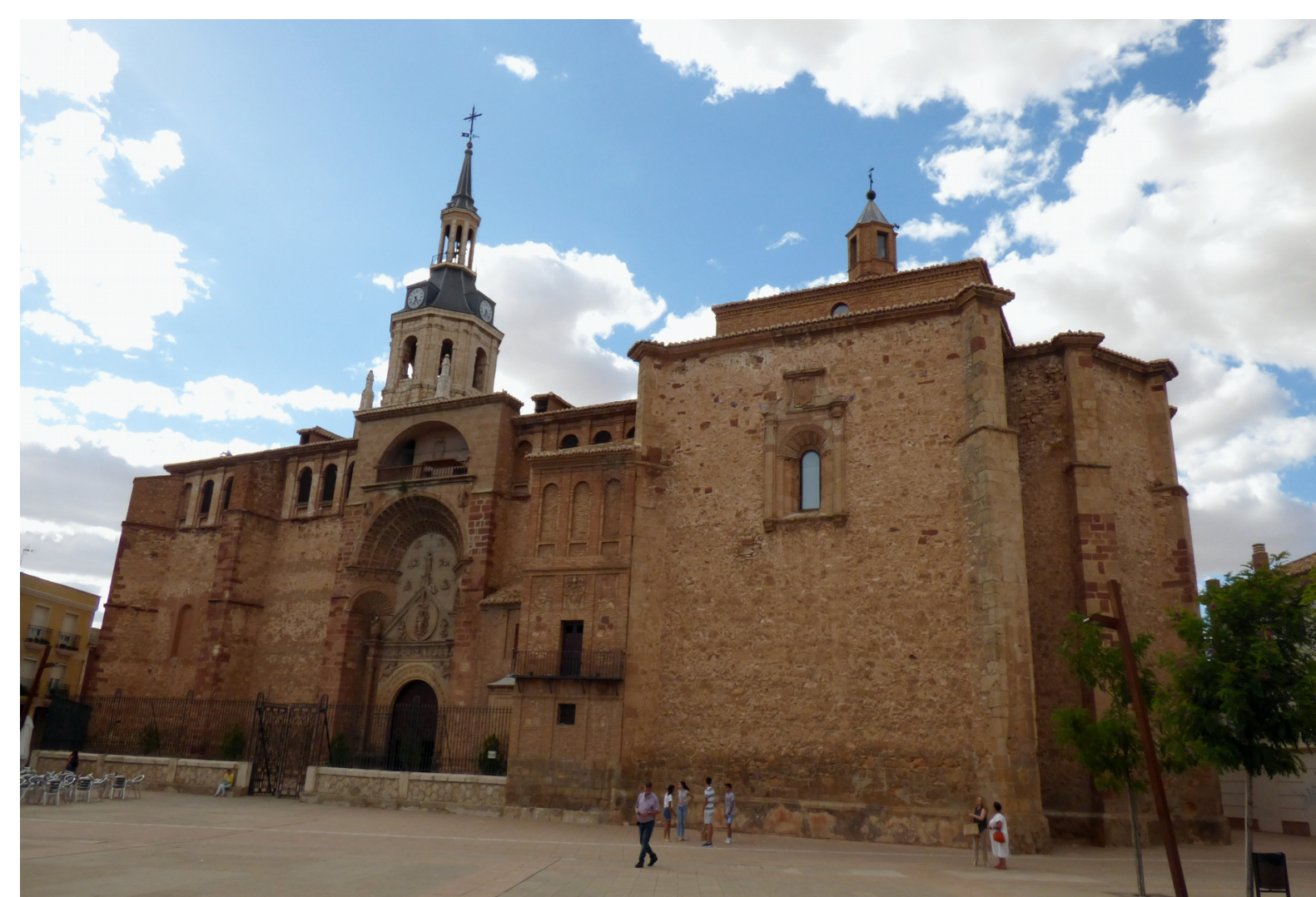

Fig. 2: Exterior de la parroquia de Nuestra Señora de la Asunción. Manzanares (Ciudad Real)

43 Tenemos muy pocos datos sobre la evolución posterior de la obra. Tan solo podemos decir que en 1577 estaba completamente terminada. Ese año los visitadores generales vieron "el altar mayor de la dicha yglesia el qual hallamos que se a hecho de nuevo despues de la visitaçion pasada sobre el qual esta un rrelicario de talla dorada y sobre el un crucifijo grande en una cruz ques de muncha deboçion (...) y se a echo e acavado la capilla mayor e crucero questa con muncha autoridad e la iglesia esta blanqueada enluçida e sin nesçesidad de ningun rreparo y en el dicho crucero ay dos bidrieras para dar luz (a la) dicha yglesia". AHN., OOMM., legajo 6084/1, sf. 


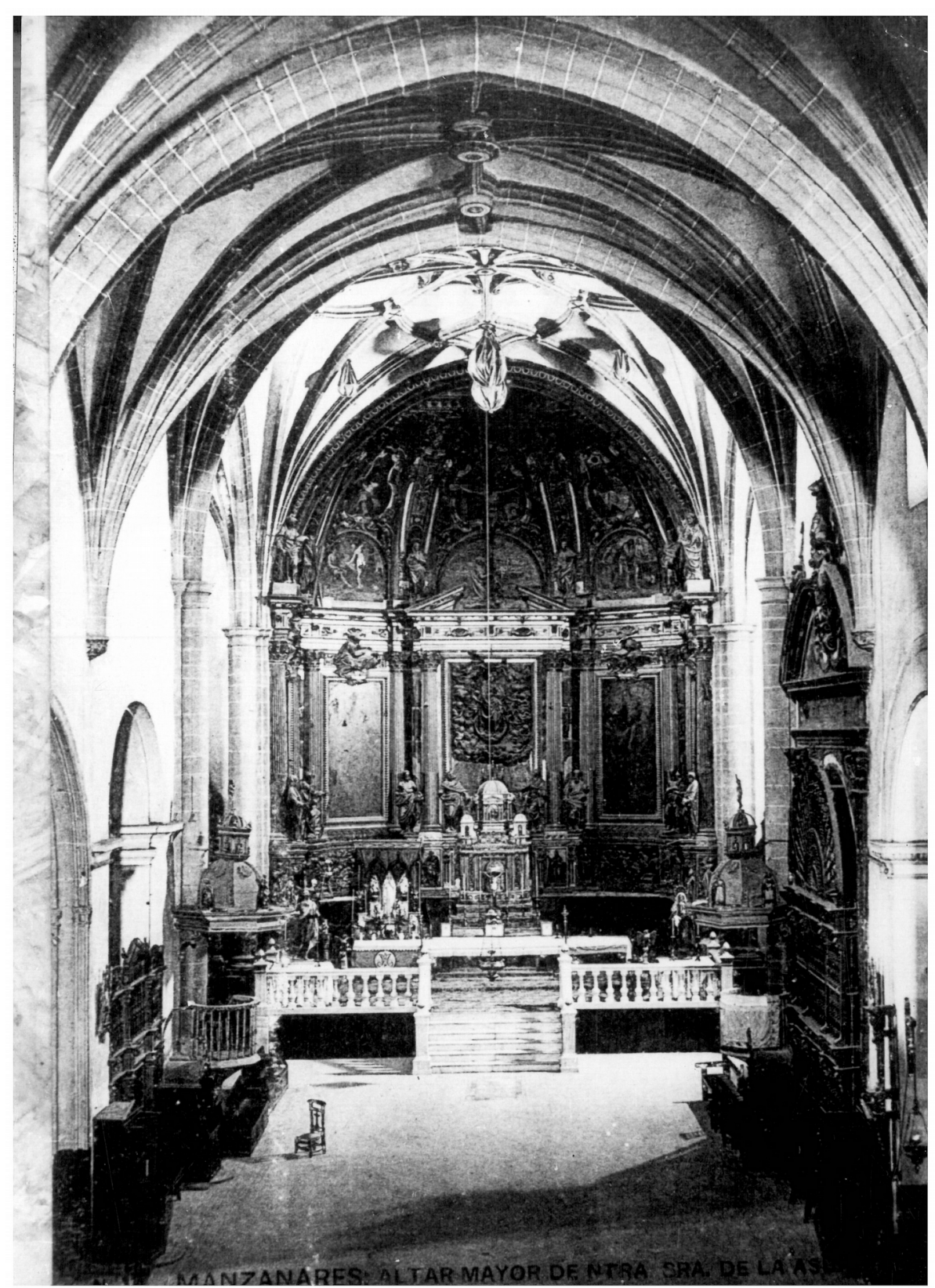

La ampliación cambió la planta del primitivo edificio, dotándolo de un ábside pentagonal y un crucero (Fig. 2). Las fotografías tomadas en el interior antes de la Guerra Civil nos muestran parte del cuerpo, el crucero y el retablo mayor (Fig. 3). El cuerpo mostraba una curiosa alternancia de soportes ya que el primer arco perpiaño de la fábrica antigua descansaba sobre ménsulas, pero el resto apeaba en pilares fasciculados. Los dos primeros tramos del cuerpo estaban cubiertos con bóvedas de terceletes, $y$ al menos una de ellas contaba con un espinazo que conectaba las claves de los arcos perpiaños; un tipo de bóveda que, a juzgar por las referencias documentales, sería sustituido en el último tramo del edificio por una estructura más compleja a base de combados. El cuerpo de la iglesia se conectaba con el crucero mediante un arco apuntado, dando paso a un espacio que combinaba el lenguaje clásico de los soportes con los planteamientos tardogóticos a la hora de concebir su bóveda. Los cuatro arcos que la enmarcaban apeaban sobre poderosas columnas toscanas adosadas a sendas pilastras del mismo orden ${ }^{44}$. La bóveda presentaba un diseño estrellado que conformaba una gran cuadrifolia a base de combados que unían los diagonales con los terceletes y estos con las claves de los arcos perimetrales. Además, en torno a la clave central se disponían unos pequeños nervios de perfil mixtilíneo que unían las ligaduras con los diagonales.

El uso de los combados en las bóvedas de crucería es una tendencia que se generalizó en el Campo de Calatrava durante la segunda mitad del siglo XVI. Dentro de esta corriente podemos

Fig. 3: Interior, antes de la Guerra Civil, de la parroquia de Nuestra Señora de la Asunción. Manzanares (Ciudad Real) distinguir entre aquellas bóvedas que carecen de combados en torno a la polo, como ocurre en la iglesia de

44 Las fotografías antiguas demuestran que, al final, las ménsulas del crucero no se hicieron de orden jónico tal y como propuso Juan de Rigoz. 
Almodóvar del Campo; y aquellas otras, como la de Manzanares, que poseen un primer orden de combados en torno a la clave principal y un segundo que conectaría los nervios diagonales con los arcos perimetrales, modelo que también podemos ver en las parroquias de Nuestra Señora de la Visitación de Argamasilla de Calatrava (primer tramo del cuerpo de la iglesia) o de San Pedro en Daimiel (crucero). Por otro lado, la utilización de columnas toscanas adosadas a pilares o pilastras es un recurso que podemos encontrar en edificios como la parroquia de Argamasilla de Calatrava o la iglesia de Madre de Dios en Almagro.

La elección de las columnas toscanas para sostener la bóveda del crucero denota un cambio de lenguaje formal con respecto al resto de soportes del edificio. No obstante, la adopción de los planteamientos renacentistas se hace especialmente evidente en la portada principal de la iglesia, conjunto que analizaremos a continuación, y en la ventana que se abre en el brazo derecho del crucero, el que da a la plaza (Fig. 4). Esta ventana se estructura en torno a un arco de medio punto abocinado decorado con casetones trapezoidales que está enmarcado por dos pares de pilastras toscanas superpuestas, las cuales descansan sobre sendos pares de ménsulas colgadas también superpuestas con perfil de voluta en $\mathrm{S}$. Por encima de éstas discurre una moldura decorada con ovas y dardos, que es una de las pocas concesiones a la ornamentación que presenta la ventana. Sobre las pilastras se dispone un entablamento con arquitrabe dividido solamente en dosfasciae y un friso completamente liso. Las jambas presentan un triple cajeado vertical, mientras que las enjutas del arco estaban decoradas con sendos tondos, aunque solo se ha conservado el que aparece a la izquierda, que luce una cruz de calatrava en su interior. El conjunto está rematado por un escudo cuartelado con las armas de Castilla y León flanqueado por dos molduras que adoptaban la forma de una cornucopia, y que están muy deterioradas, sobre todo la que aparece a la derecha, de la que tan solo podemos ver la parte superior.

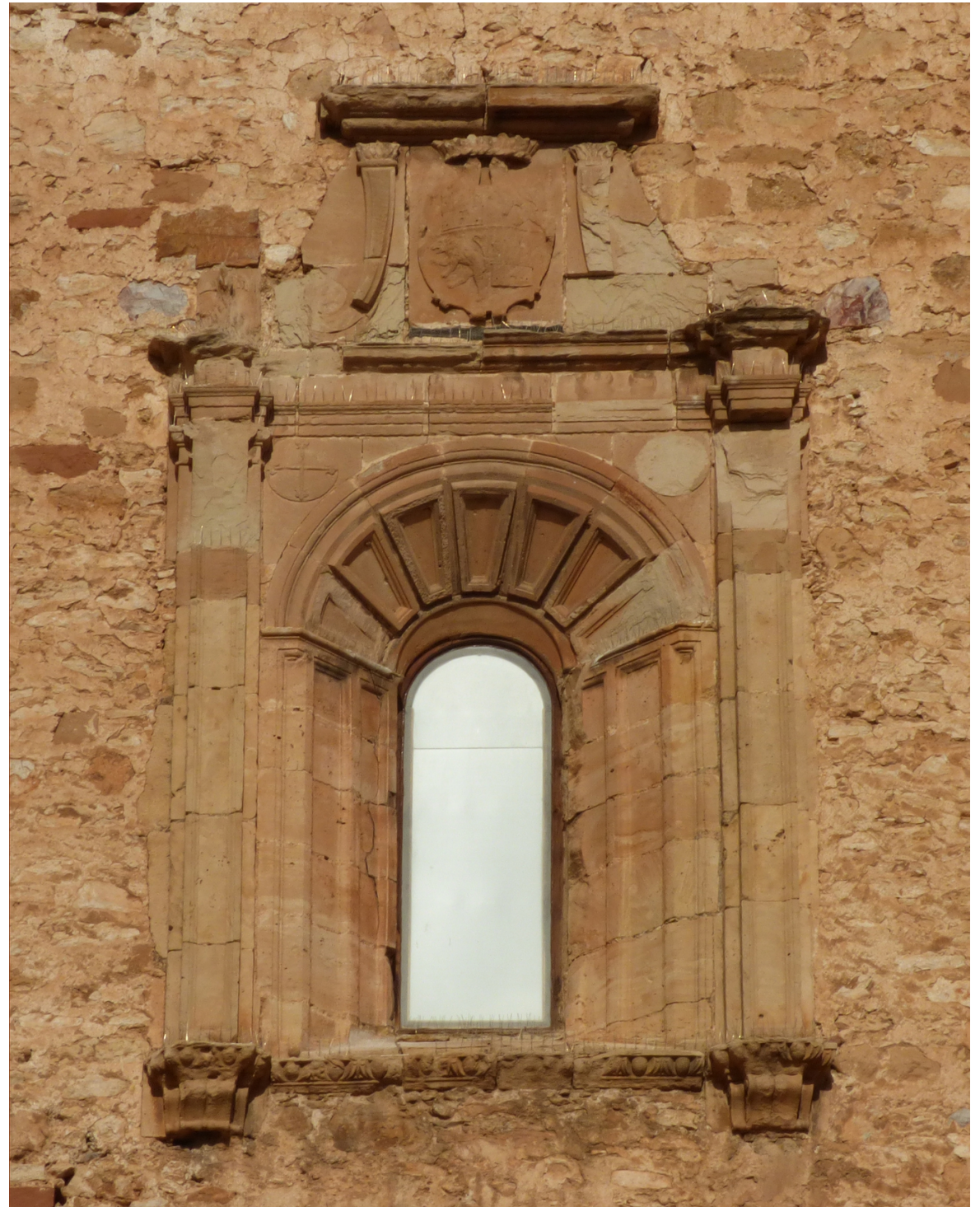

Fig. 4: Ventana del crucero de la parroquia de Nuestra Señora de la Asunción. Manzanares (Ciudad Real)

Fig. 5: Portada principal de la parroquia de Nuestra Señora de la Asunción. Manzanares (Ciudad Real) 


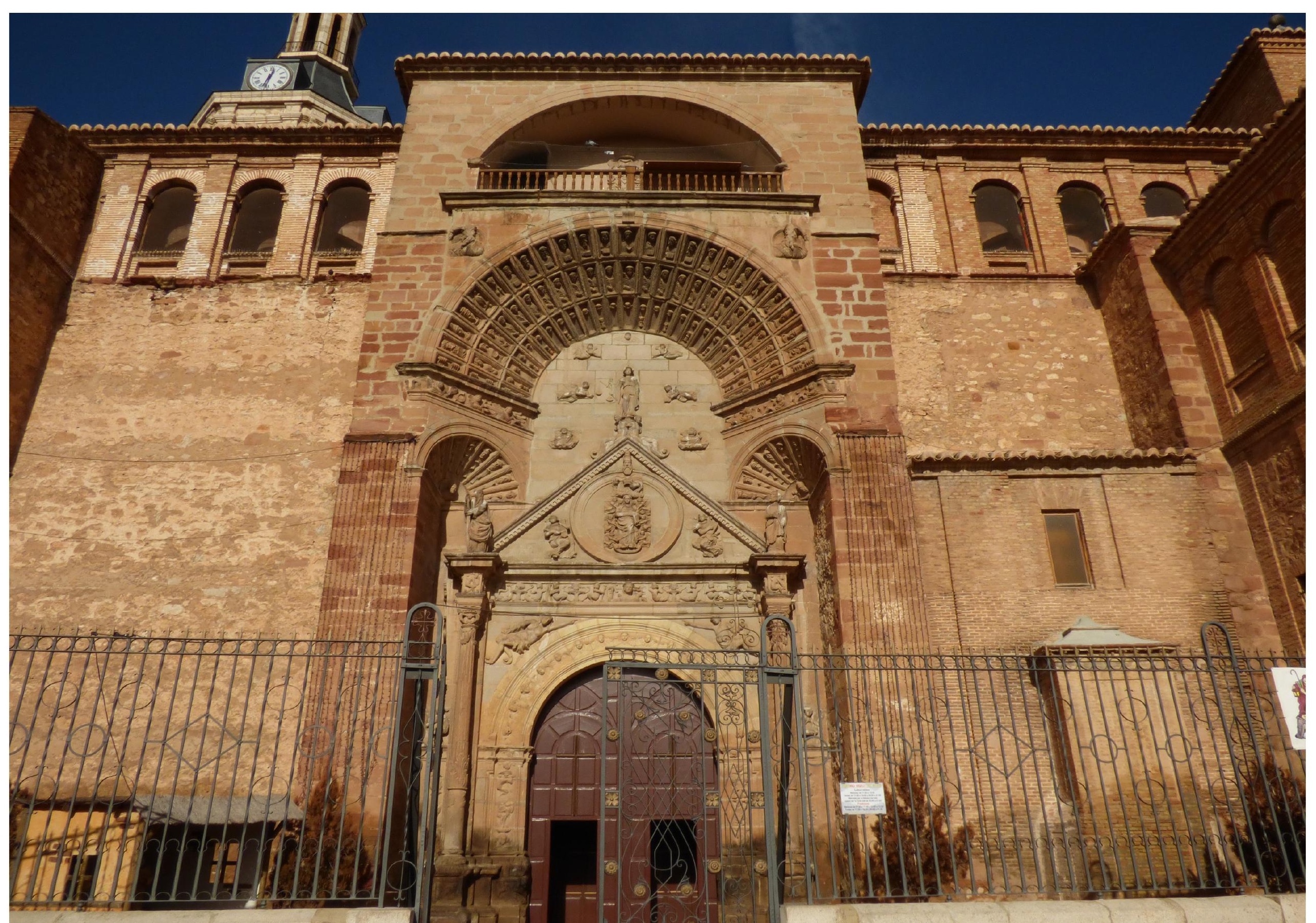




\section{LA PORTADA PRINCIPAL}

La parroquia de Manzanares posee uno de los mayores conjuntos escultóricos, en lo que a escultura monumental se refiere, de todo el Campo de Calatrava. Nos estamos refiriendo a su portada principal. Hasta ahora se desconocía quién había diseñado o realizado esta obra, adjudicándose el conjunto a Enrique Egas el $\mathrm{Mozo}^{45}$, pero afortunadamente la documentación que hemos consultado nos ha proporcionado el nombre de su autor, un maestro que sería el propio Alonso Galdón. El cuestionario presentado por parte del concejo para apoyar su petición de ayuda económica incluía un apartado en el que se preguntaba a los testigos por el valor de las primicias que percibía la iglesia ${ }^{46}$, y Alonso Galdón respondió que "las dichas dos partes valdran dozientas fanegas de todo pan arriba porqueste testigo las cogio dos años para en pago de una portada que hizo en la dicha yglesia". La respuesta no especifica qué portada había realizado, pero si tenemos en cuenta la cantidad de recursos que había requerido el proyecto, ya que al menos se habría destinado toda la renta que tenía adjudicada la iglesia para hacer frente a los gastos ordinarios de su fábrica durante dos años ${ }^{47}$, parece obvio que estamos ante una obra de gran

45 SAINZ MAGAÑA, E y HeRRERA MALDONAdo, E.: "Arte Moderno", en Ciudad Real y su provincia, Sevilla, Gever, 1996-97, p. 132.

46 La iglesia de Manzanares, como la mayor parte de las parroquias del Campo de Calatrava, contaba con dos tercios de las primicias para sufragar sus gastos. Este impuesto eclesiástico implicaba el pago de cierta cantidad de cereal siempre y cuando la cosecha alcanzase un determinado volumen. En concreto, los vecinos de Manzanares debían abonar media fanega de grano si la cantidad recogida llegaba a quince.

47 Tomando como referencia el valor de las distintas partidas de trigo y cebada que vendieron los mayordomos podemos afirmar que el valor de las primicias de dos años (es decir, 400 fanegas de pan por mitad, trigo y cebada) podía oscilar entre los 84000 y los 90000 maravedís. Debemos tener en cuenta que el testimonio no dice que el coste de la portada equivaliese al valor de las primicias, sino que esta renta se le entregó en pago por su labor, por lo que perfectamente esta obra podría haber costado más. envergadura, y la portada principal es la única que presenta esta característica $^{48}$. Por otro lado, la referencia que acabamos de aportar se limita a hablar de la ejecución material de la portada, sin hacer referencia a la traza de la misma, aspecto que aún sería necesario precisar. Sin embargo, y a la espera de nuevas fuentes documentales que aclaren este asunto, pensamos que su diseño podría ser obra del propio Alonso Galdón a juzgar por el uso recurrente de un elemento decorativo, los casetones. En este sentido, nos gustaría recordar que el primer proyecto que presentó el maestro para la torre de la parroquia de La Solana poseía bóvedas decoradas con estos motivos, aunque luego terminara eliminándolos tras el dictamen de Alonso de Covarrubias ${ }^{49}$.

El conjunto se levanta en el tercer tramo del cuerpo del edificio y posee dos partes perfectamente diferenciadas (Fig. 5). La zona más importante consta de un gran arco cimbra de medio punto con el intradós abocinado y decorado con casetones que presentan decoración escultórica. Este arco de enormes dimensiones se inserta en los contrafuertes del edificio y descansa sobre dos trompas que ejercen de elemento de transición entre la superficie del muro y los propios contrafuertes, y que reproducen la decoración a base de casetones con motivos escultóricos. Bajo esta estructura nos encontramos con la portada propiamente dicha, que se organiza en torno a un arco de medio punto que descansa sobre jambas apilastradas y que está enmarcado por dos pilastras con columnas antepuestas colocadas sobre un amplio plinto. Las columnas presentan un perfil abalaustrado bastante sencillo ${ }^{50}$ y sus capiteles están decorados con

48 La iglesia cuenta en la actualidad con un acceso a los pies del edificio, en la base de la torre, que es un simple arco de medio punto y con otro en el lado de la umbría.

49 MOLINA CHAMIZO, P.: Op. cit., p. 29

50 El cuarto inferior del fuste es liso pero el resto, que presenta un arranque ligeramente bulboso enmarcado por grandes hojas de acanto, es acanalado y cuenta con unos 
cuatro figuras humanas de aspecto fitomorfo entre las que se disponen cabezas de león. Las pilastras, por su parte, tienen el fuste completamente decorado con grutescos ordenados a candelieri, motivos que permanecen semiocultos al quedar detrás de las columnas. Por encima de los capiteles discurre el entablamento, con un friso ricamente ornamentado, y sobre él nos encontramos con un amplio frontón triangular.

En origen, este enorme conjunto, que está rematado por una cornisa, sobresaldría ligeramente por encima del muro de la iglesia, ya que el edificio carecía de la galería a base de arcos de medio punto realizados en ladrillo que podemos ver en la actualidad. La altura original de sus paramentos se correspondería con la moldura superior que todavía podemos observar en los contrafuertes y sobre esta moldura se levantó el segundo cuerpo de la portada, que se concibió como una gran tribuna que se abre a la plaza ${ }^{51}$. La portada y el gran arco cimbra tuvieron que realizarse entre 1547, año en el que Alonso conoció la localidad, y 1560, fecha en la que comenzaron las tareas para levantar la nueva capilla mayor; pero la tribuna debió levantarse al mismo tiempo que la galería que remata los muros del cuerpo de la iglesia. Una estructura, ideada para airear las bóvedas, que empezó a construirse a principios del siglo XVII y sirvió para igualar la altura del edificio, elevando el cuerpo hasta equipararlo con la capilla mayor diseñada por Egas el Mozo ${ }^{52}$.

bastones que recorren la mayor parte de su desarrollo vertical. Las columnas, además, están decoradas con dos guirnaldas que penden de sendas argollas colocadas bajo las molduras que rematan el fuste, mientras que en la parte inferior del mismo cuentan con unas pequeñas cabezas de animal (probablemente de león) muy deterioradas que sostienen unas cartelas.

51 Este segundo cuerpo está realizado con sillares de aspecto y formato diferente a los del gran arco cimbra.

52 La galería empezó a levantarse por decisión de don Gómez de Ávila, marqués de Velada, comendador en esos momentos de Manzanares, que además solicitó para ello
Esta magnífica obra no tiene parangón en todo el Campo de Calatrava y tampoco en las comarcas vecinas. Tan solo la portada principal de la parroquia de Villamanrique, en el Campo de Montiel (Ciudad Real), guarda un cierto paralelismo con la de Manzanares porque también posee un segundo cuerpo que se dispone sobre el arco cimbra que cobija la estructura, y que en este caso se concibió como una logia formada por cinco arcos de medio punto ${ }^{53}$. En cambio, la portada de Manzanares presenta un importante parecido con el ochavo del antiguo convento dominico de La Guardia (Jaén), obra diseñada por Andrés de Vandelvira que cuenta con una bóveda de cuarto de esfera decorada con casetones sostenida por dos trompas aveneradas.

Como ya hemos dicho, la portada es uno de los conjuntos escultóricos más importantes del Campo de Calatrava y acoge un complejo programa iconográfico. Las enjutas del arco de entrada albergan dos personajes, uno femenino (izquierda) y otro masculino (derecha), que carecen de cualquier elemento que nos sirva para identificarlos. Los dos van ataviados de la

la colaboración del concejo, tal y como se recoge en un decreto del ayuntamiento fechado el 2 de septiembre de 1612. El texto afirmaba que "por quanto el señor Marques de Velada comendador de la encomienda desta villa quiere proseguir la obra de la iglesia mayor desta villa y levantar la obra vieja y emparejalla con la nueva arqueándola e haciendo lo demás necesario a su costa en lo ques maestros e materiales de todo lo necesario e para queste negocio tenga efeto la parte de el dicho señor marques a pedido a este concexo que de carros e vagaxes para traer piedra cal teja arena y ladrillos por esta carta se decreta quel dicho consejo dara los dichos carros e vagajes para el dicho efeto y esto se asigura se cumplirá a el dicho señor marques y a los oficiales que hicieren postura e vaxas en la dicha ovra para lo qual obligaron los vienes e rrentas deste consejo". AHN., OOMM., Archivo Histórico de Toledo, legajo 37055, sf.

53 El Campo de Montiel nos ofrece varios ejemplos de portadas inscritas en un arco cimbra, pero la de Villamanrique es la única que cuenta con este segundo cuerpo. 
misma forma y mantienen la misma postura ${ }^{54}$, presentando además la particularidad de poseer unos pies vegetalizados; característica ésta, la de poseer extremidades fitomorfas, que es común a muchas de las representaciones de la portada.

El friso está presidido por el busto de una mujer que luce una larga melena y que empuña una espada con la mano derecha, por lo que podríamos considerarla una representación de la Justicia. El resto del friso está decorado con una serie de representaciones humanas de carácter híbrido que están dispuestas conformando parejas en torno a cuatro vasos que sirven de soporte a una calavera o un querubín.

El frontón nos muestra una imagen de la coronación de la Virgen inscrita en un gran tondo. María asciende a los cielos sostenida por seis ángeles y, sobre ella, podemos ver a Dios Padre, colocado sobre una nube y representado de medio cuerpo, que levanta la mano derecha en actitud de bendecir, mientras sostiene con la izquierda la corona que va a imponer a María. La escena está enmarcada por dos ángeles que, colocados a ambos lados del tondo, tocan instrumentos musicales, en concreto un salterio y un arpa. El frontón está flanqueado por dos esculturas exentas de cuerpo entero que están colocadas sobre la parte del entablamento que permanece en resalte sobre las columnas que enmarcan el arco de entrada. Se trata de San Pablo, que permanece apoyado en una espada de gran tamaño (columna izquierda) y San Pedro (columna derecha) que porta una llave también de grandes dimensiones.

54 Ambas representaciones lucen un simple paño que les deja al descubierto el torso y extienden uno de sus brazos en dirección hacia el otro, señalando con el dedo índice hacia la clave del arco.

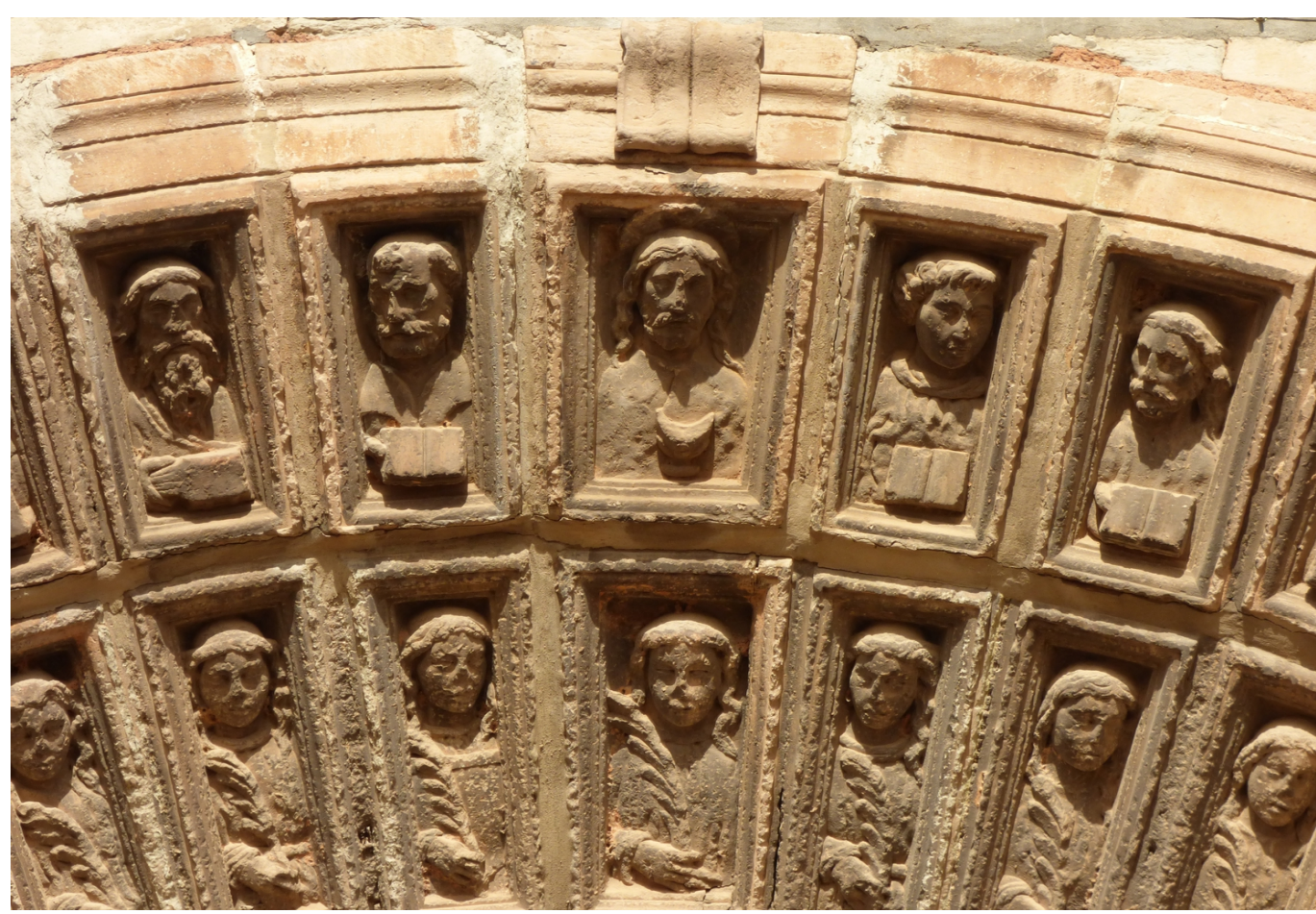

Fig. 6: Detalle de los personajes del arco cimbra de la portada principal de la parroquia de Nuestra Señora de la Asunción. Manzanares (Ciudad Real)

Sobre el frontón, además, nos encontramos con una mujer representada de cuerpo entero que permanece de pie sobre un pequeño pedestal. Va vestida con una larga túnica que cubre por completo su anatomía, excepción hecha de la pierna derecha que está ligeramente adelantada y queda al descubierto desde la rodilla. En su mano derecha porta una balanza, elemento que nos serviría para identificarla como otra representación de la Justicia, y a sus pies, a ambos lados del pedestal, aparecen dos figuras humanas con las extremidades vegetalizadas que permanecen sentadas sobre la cornisa que remata el frontón. 


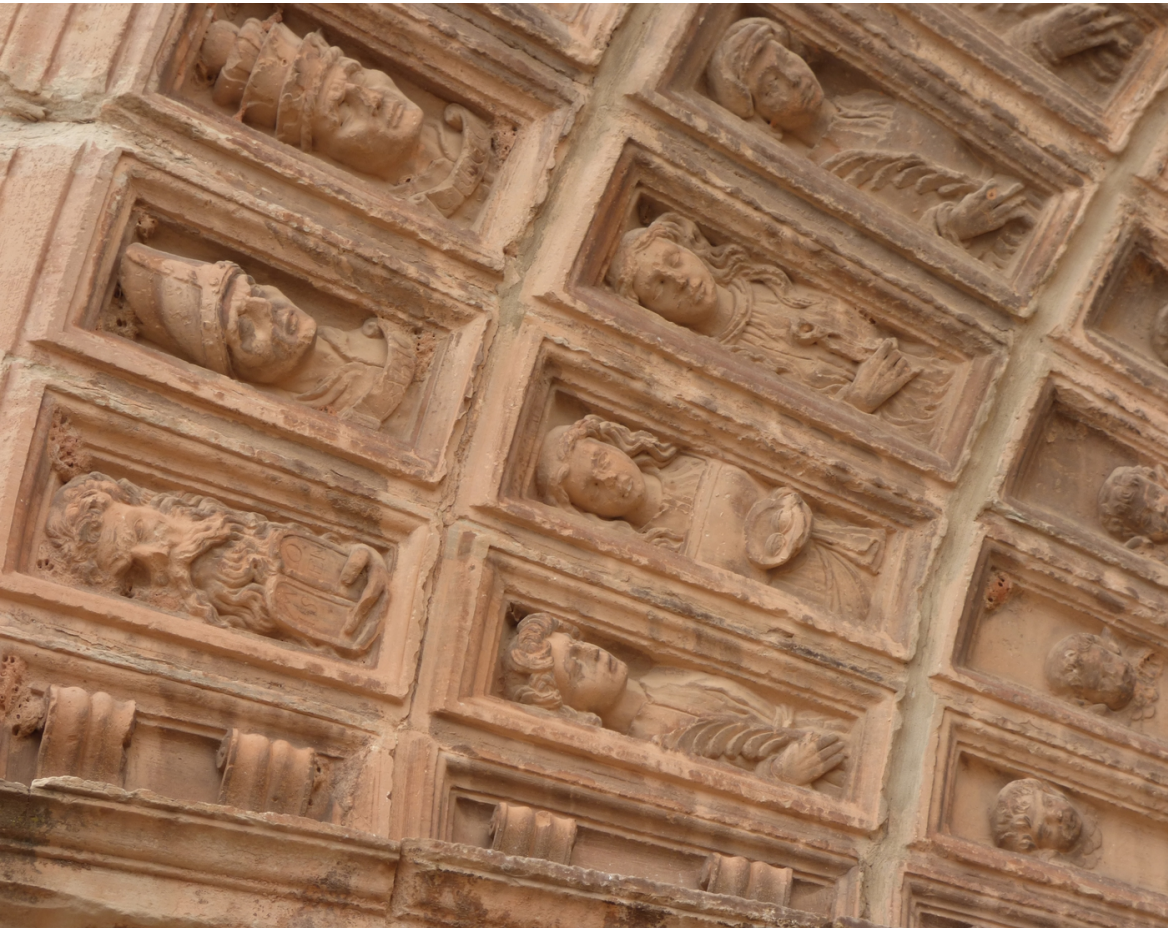

Fig. 7: Detalle de los personajes del arco cimbra de la portada principal de la parroquia de Nuestra Señora de la Asunción. Manzanares (Ciudad Real)

La imagen femenina que acabamos de mencionar está rodeada por siete ángeles realizados en distintos formatos. El que está situado justo en la vertical sobre su cabeza responde al típico modelo de querubín, o cabeza dotada de alas, y resulta bastante tosco. Los cuatro que vienen a continuación (dos a cada lado) son imágenes de cuerpo entero y los dos últimos de medio cuerpo, con la particularidad de que estos están colocados sobre una nube. Tres de los cuatro ángeles que están representados de cuerpo entero llevan en sus manos sendos cuernos, aunque solo uno está tocándolo, concretamente el primero por la derecha, mientras que su compañero de la izquierda se lo acerca a la boca, pero no llega a soplar ${ }^{55}$

Las arquivoltas del gran arco cimbra nos muestran un amplio repertorio iconográfico en el que tienen cabida personajes bíblicos, tanto del Viejo como del Nuevo Testamento, así como santos y santas de la tradición cristiana, repertorio que se completa con las figuras que se labraron en las trompas y en las propias enjutas del arco. La primera arquivolta está presidida por la imagen de Cristo que ocupa el casetón central ${ }^{56}$ (Fig. 6) y a continuación nos encontramos con los apóstoles, distribuidos en dos grupos de seis a ambos lados del Redentor ${ }^{57}$, y con los símbolos de los cuatro evangelistas ${ }^{58}$. La simetría que hemos visto a la hora de distribuir

55 No obstante, el ángel que carece de este elemento pudo haberlo llevado porque ha perdido una de sus manos.

56 Su cabeza está enmarcada por un nimbo crucífero y frente a su pecho se labró un cáliz lo que confiere a la representación un marcado carácter eucarístico.

57 La mayor parte carece de elementos o de rasgos físicos que nos permitan identificarlos, reproduciendo casi todos el mismo modelo iconográfico. Se trata de personajes de larga barba que llevan un libro abierto en la mano. En realidad, solo podemos identificar a cuatro: San Pedro, San Juan, Santiago y Judas. San Pedro y San Juan aparecen a izquierda y derecha de Cristo, respectivamente. San Pedro no porta ningún elemento, pero su calva, con un mechón de pelo sobre la frente, es muy similar a la que presenta la imagen que aparece sobre la columna derecha de la portada, lo que nos permitiría identificarlo. San Juan, siguiendo la tradición evangélica, presenta un rostro juvenil e imberbe, siendo el único apóstol que carece de barba. Santiago, por su parte, es el tercer apóstol que aparece a la izquierda de Cristo y lleva un sombrero que luce la típica concha de peregrino. Finalmente, Judas es el último de los que están representados a la derecha de Cristo e identificarle es bastante sencillo ya que lleva en su mano la bolsa en la que según el relato evangélico guardó las treinta monedas de plata que recibió a cambio de entregar a Jesús. Además, el apóstol gira ostensiblemente la cabeza hacia el lado opuesto al que se encuentra Cristo, un gesto que trataría de reflejar su papel de traidor.

58 A la izquierda aparecen el león de San Marcos y el águila de San Juan, y a la derecha el 
estos personajes se rompe en el siguiente casetón ya que en el lado izquierdo nos encontramos con un padre de la iglesia latina, San Gregorio, $y$ en el derecho con un personaje del Antiguo Testamento, Aaron, pero vuelve a retomarse en los siguientes casetones, ya que volvemos a encontrarnos con otro padre de la Iglesia, San Hilario (izquierda) y San Ambrosio (derecha), y con otros dos personajes del Antiguo Testamento, Moisés (izquierda) y Abraham (derecha) (Fig. 7).

La segunda arquivolta acoge las imágenes de veintitrés vírgenes mártires. De todas ellas, solo cuatro van acompañadas de un elemento que nos permita identificarlas. Se trata de Santa Lucía, que lleva la característica bandeja con sus ojos; Santa Apolonia, que porta unas tenazas; Santa Águeda, que muestra sus dos pechos en otra bandeja, y Santa Inés, con un cordero que asoma la cabeza a su lado ${ }^{59}$. El resto solo lleva una palma en clara alusión a su martirio.

Finalmente, la tercera y última arquivolta, está ocupada por veintitrés querubines que pueden ir acompañados o no de un elemento vegetal que aparece debajo de ellos, estableciéndose una curiosa alternancia entre casetones con querubín y casetones que además del querubín presentan este elemento, una alternancia que se rompe en dos ocasiones al encontrarnos con dos casetones consecutivos que solo muestran un ángel.

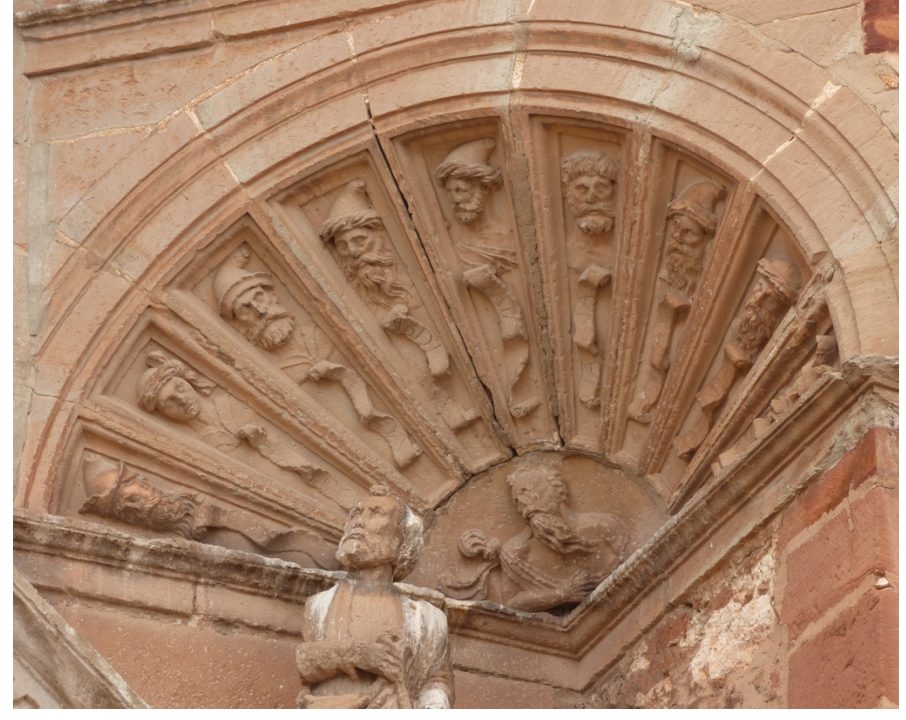

Fig. 8: Trompa derecha de la portada principal de la parroquia de Nuestra Señora de la Asunción. Manzanares (Ciudad Real)
Las trompas que sostienen el arco albergan diez personajes cada una. E primero, que está representado de medio cuerpo, ocupa el arranque de la propia trompa, mientras que los demás aparecen encima enmarcados por casetones que se disponen de forma radial, personajes que además están identificados mediante una filacteria que recorre longitudinalmente la mayor parte del casetón. En la trompa izquierda nos encontramos con San Agustín, identificado por la correspondiente inscripción, y sobre él podemos contemplar los bustos de nueve personajes del Antiguo Testamento: Zacarías, Daniel, Natan, Elías, José, Isaac, Malaquías, Miqueas y Joel. La figura que aparece en el arranque de la trompa derecha carece de inscripción identificativa, aunque pensamos que podría tratarse de San Jerónimo $0^{60}$, y encima vemos otros nueve personajes del Antiguo Testamento: Jeremías, Ageo, Amos, Abdías, Isaías, Jonás, Óseas, Sofonías y Habacuc (Fig. 8). Sobre cada trompa discurre un friso con tres ángeles representados $\mathrm{de}$ medio cuerpo. Todos sostienen una filacteria donde puede leerse una inscripción alusiva a María, filacterias a las que habría que toro de San Lucas y el ángel de San Mateo.

59 Santa Lucía y Santa Apolonia ocupan respectivamente el tercer y el cuarto casetón empezando por la izquierda, mientras que Santa Águeda y Santa Inés aparecen en el tercero y el quinto empezando por la derecha.
60 Nos encontramos ante un hombre de cierta edad, calvo y con barba, que va vestido con una túnica anudada sobre el hombro derecho, dejando al descubierto el otro. Aunque ya hemos dicho que no hay una inscripción que nos permita identificarlo parece lógico pensar, tanto por la indumentaria como por el aspecto, que se trata de San Jerónimo. 
añadir una cuarta dispuesta al principio del propio friso ${ }^{61}$. El programa iconográfico de la portada se completa con las imágenes de David y Salomón que aparecen en las enjutas del arco cimbra colocadas, que no inscritas, sobre sendos tondos e identificadas por dos cartelas en las que se labraron sus respectivos nombres.

El conjunto que acabamos de describir es un breve compendio de la doctrina católica que pretendía mostrar al fiel las imágenes de los principales protagonistas y exegetas del dogma. Dentro del programa se pueden distinguir dos líneas argumentales: la exaltación de la figura de María y la necesidad de enlazar la tradición neotestamentaria con la veterotestamentaria, un doble discurso que además está cargado de resonancias apocalípticas. El conjunto hace referencia a dos de los grandes misterios marianos, la Asunción y la Coronación, ejemplificados en la imagen de María que aparece en el frontón y en las inscripciones que portan los ángeles del friso que discurre por encima de las trompas, inscripciones que también tienen resonancias inmaculistas.

La intención de enlazar el Nuevo con el Viejo Testamento queda de manifiesto en los personajes que aparecen representados tanto en el arco cimbra como en las trompas, donde nos encontramos con un nutrido grupo presidido por Cristo y sus doce apóstoles, siguiendo una disposición

61 En el friso izquierdo, de izquierda a derecha, podemos leer: PVLCHRA VT LVN(A), ELECTA VT SOL, TERIBILIS VT CASTRORV(M) y ACIES ORDINATA, mientras que en el derecho, en sentido contrario nos encontramos con QVE EST ISTA, Q(VAE) PROGREDITVR, QVASI AVRORA y CONSURGENS. Todas juntas conforman un versículo del Cantar de los Cantares alusivo al dogma de la Asunción de María, pero que curiosamente están dispuestos al revés ya que la parte inicial del texto es la que aparece en el friso de la derecha. Su traducción sería la siguiente: “¿Quien es ésta que se descubre como el alba, hermosa como la luna, escogida como el sol, terrible como los escuadrones?" (Cant. 6:9). que nos remite a la Última Cena, pero también con varios Padres de la Iglesia y con numerosos personajes del Antiguo Testamento, sobre todo patriarcas y profetas, figuras que ejercen como intérpretes y soportes de la doctrina cristiana o como precursores de la misma, respectivamente; de ahí que se coloquen en las trompas y en la parte baja del arco cimbra. Dentro de este conjunto destacan dos reyes como David y Salomón que forman parte de la genealogía de Cristo y que servirían para poner de manifiesto la pertenencia de Jesús a la estirpe real de Israel.

Por otra parte, las resonancias apocalípticas, que están presentes en la propia representación de María ${ }^{62}$, resultan más evidentes en la imagen de la justicia que corona el frontón ya que está rodeada por siete ángeles, tres de los cuales sostienen cuernos a modo de trompetas.

Afortunadamente la portada presenta un buen estado de conservación, sobre todo si tenemos en cuenta las enormes destrucciones ocasionadas en el edificio durante la Guerra Civil. Las fotografías tomadas antes del conflicto nos permiten afirmar que, básicamente, el conjunto que podemos contemplar en la actualidad es el mismo que el que se levantó en el siglo XVI, pero lo cierto es que también presenta pequeñas intervenciones que debieron realizarse cuando se restauró el edificio en los años cuarenta, intervenciones que podían estar relacionadas con los daños ocasionados durante la contienda, pero también con el deterioro que presentaba la estructura debido al paso del tiempo. Si revisamos la fotografía publicada por El pueblo manchego el 8 de agosto 1933 (Fig. 9) podremos comprobar que la moldura que remataba el entablamento estaba

62 La presencia del creciente lunar a los pies de la Virgen es un detalle que la vincula con la mujer apocalíptica, siguiendo una tendencia muy común en el arte español a la hora de representar la Asunción. GARCIA MAHIQUES, R.: "Perfiles iconográficos de la Mujer del Apocalipsis como símbolo mariano (I): Sicut mulier amicta sole et luna sub pedibus eius", Ars longa: cuadernos de arte, no 6, 1995, pp. 187-197. 


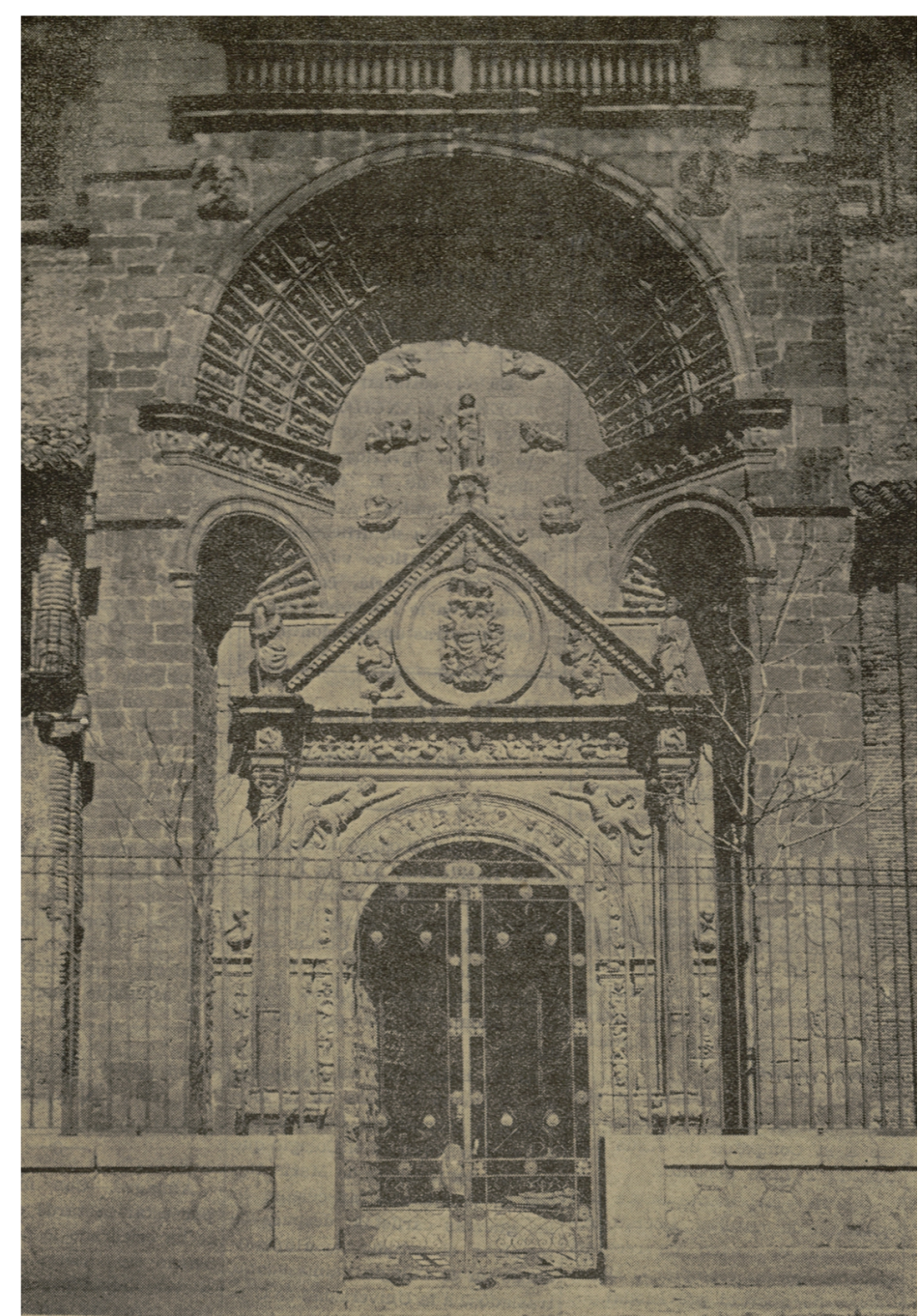

Fig. 9: Portada principal de la parroquia de Nuestra Señora de la Asunción. Manzanares (Ciudad Real). El pueblo Manchego (08/09/1933). Hemeroteca Municipal de Madrid

Fig. 10: Justicia (friso) en la portada principal de la parroquia de Nuestra Señora de la Asunción. Manzanares (Ciudad Real) ya muy deteriorada, algo que no ocurre en la actualidad, por lo que resulta evidente que fue sustituida. Además, tanto los distintos tonos de la piedra como el aspecto de algunos de los motivos nos hace pensar que no son originales, como ocurre con varias de las dovelas del arco de entrada (y por

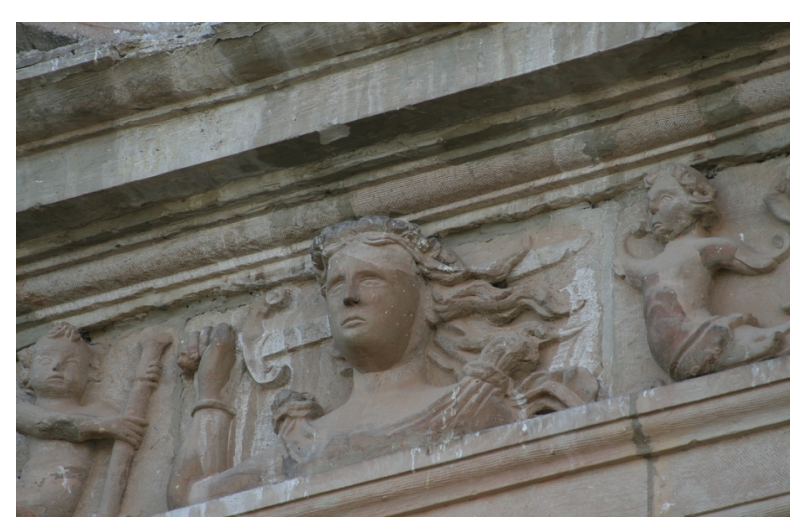
tanto con los querubines que aparecen en ellas) y con el rostro de la imagen femenina que aparece en el centro del friso (Fig. 10).

No obstante, y con independencia de estas intervenciones, lo cierto es que la portada es la mayor y mejor muestra de la escultura monumental del Renacimiento en todo el Campo de Calatrava. Los personajes representados en este conjunto nos proporcionan una enorme gama de rasgos físicos, de gestos y de tocados, realizados con un gran detallismo y finura. Todos los apóstoles, santos y personajes del Antiguo Testamento tienen rasgos diferentes, e incluso las santas mártires del gran arco cimbra tienen también rostros ligeramente distintos, un detalle que nos estaría hablando de un evidente interés por individualizarlas, aunque solo se decidiera identificar a cuatro de ellas labrando sus respectivos símbolos. Por otra parte, la finura a la hora de realizar los rostros se aprecia mucho mejor en los personajes de las trompas por su mejor estado de conservación. Sin embargo, el conjunto no es completamente homogéneo ya que también podemos encontrarnos con figuras más toscas, como la mayor parte de los ángeles que se distribuyen en torno a la imagen de la Justicia que aparece sobre el frontón, algo que podría explicarse por la existencia de intervenciones posteriores que añadiesen elementos al programa original o por efecto de alguna restauración, como la llevada a cabo tras la Guerra Civil. 


\section{BIBLIOGRAFÍA}

BARRANQUERO CONTENTO, J.J.: "La arquitectura en el Campo de Calatrava (1500-1570): de Juan de Baeza y Antón Egas a Enrique Egas el Mozo y Martín de Zalvilla", Archivo Español de Arte, tomo 86, no 341, 2013.

: "La fábrica de la Madre de Dios (Almagro): el largo proceso constructivo de un edificio singular", I Congreso Nacional Ciudad Real y su provincia, Vol. 3, Ciudad Real, Instituto de Estudios Manchegos, 2015.

: "Canteros vascos en el Campo de Calatrava durante la segunda mitad del siglo XVI", Ars Bilduma: Revista del Departamento de Historia del Arte y Música de la Universidad del Pais Vasco, no 6, 2016.

FERNÁNDEZ-PACHECO SÁNCHEZ-GIL, C.: “EI urbanismo en la Orden de Calatrava: el ejemplo de Manzanares (siglos XIII-XVII), en ALIA MIRANDA, F. y ANAYA FLORES, J.: I Congreso Nacional Ciudad Real y su provincia, Ciudad Real, Instituto de Estudios Manchegos, 2015.

GARCIA MAHIQUES, R.: "Perfiles iconográficos de la Mujer del Apocalipsis como símbolo mariano (I): Sicut mulier amicta sole et luna sub pedibus eius", Ars longa: cuadernos de arte, no 6, 1995.

SAINZ MAGAÑA, E y HERRERA MALDONADO, E.: "Arte Moderno", en Ciudad Real y su provincia, Sevilla, Gever, 1996-97.

MOLINA CHAMIZO, P.: De la fortaleza al templo. Arquitectura religiosa de la Orden de Santiago en la provincia de Ciudad Real (siglos XV-XVIII), Tomo II, Ciudad Real, Diputación Provincial de Ciudad Real, 2006.
PRETEL MARIN, A.: Alcaraz en el siglo de Andrés de Vandelvira, el bachiller Sabuco y el preceptor Abril (Cultura, sociedad, arquitectura y otras bellas artes en el Renacimiento), Albacete, Diputación Provincial de Albacete, 1999. 